\title{
THE YEAR OF ENDURING COVID-19: TYPOLO- GY OF ATTITUDES DISPLAYED BY HEALTH CARE PROFESSIONALS IN UKRAINE
}

\author{
LARYSA KLYMANSKA \\ Department of Sociology and Social Work \\ Lviv Polytechnic National University \\ vul. Konovaltsia, 4 Lviv, 79013 Ukraine \\ Email address: larysa_kl@ukr.net \\ ORCID: https://orcid.org/0000-0002-3693-7503 \\ MARYNA KLIMANSKA \\ Faculty of Philosophy, Department of Psychology \\ Ivan Franko National University of Lviv \\ vul. Universytetska 1, Lviv, 79000 Ukraine \\ E-mail address: marina.klimanska@gmail.com \\ ORCID: https://orcid.org/0000-0002-3047-2346 \\ INNA HALETSKA \\ Faculty of Philosophy, Department of Psychology \\ Ivan Franko National University of Lviv \\ vul. Universytetska 1, Lviv, 79000 Ukraine \\ E-mail address: innahaletska@gmail.com \\ ORCID: https://orcid.org/0000-0002-9319-2229
}

\begin{abstract}
Aim. The article presents identification and construction of the typology of attitudes of health care professionals in Ukraine to the current COVID-19 situation and vaccination process.

Methods. Transcripts of 49 semi-structured interviews subjected to thematic analysis constituted the subject matter of the analysis. On the basis of the categories identified within the thematic analysis process, a typology was developed, with due account of two parameters: the idea about the origin of the virus: artificial or natural, and the attitude of the informants to the policy (implementation of policy decisions) chosen by the authorities to fight the virus. Combination of these two parameters gives four standpoints - types of attitude of health care professionals to the risks associated with COVID-19.

Results and conclusion. Analysis of the results has enabled to outline the problem field for assessing the risk of COVID-19, which includes three topics, as well as to point
\end{abstract}


out four typical standpoints in the attitude displayed by health care professionals that are marked as "magical thinking," "technological thinking," "negativistic thinking," "critical thinking."

Originality. The research was conducted during the third wave of coronavirus in Ukraine, therefore, it reflects the analysed opinions of health care professionals about the threat of COVID-19 and vaccination process. The fact that the research was performed using qualitative methods ensured focusing on subjective peculiarities of the perception of changes in the COVID-19 situation.

Key words: COVID-19 pandemic, qualitative research methods, threat perception, vaccination, preventive health behaviour, conspiracy theories, health care professionals, public health

\section{PROBLEM STATEMENT}

A year and a half of the global pandemic has disconcertingly changed A the lives of people. Quarantines which regularly grow into lockdowns, social distancing, transfer of work and studies into the online format, rigid restrictions for moving across the world, standstill and transformation of businesses and economy in some countries and the world in general, as well as wearing a mask as a norm of life have become common things of daily life. The threat of getting infected with a strange virus, due to objective severity of the course of the disease and unfavourable long-term consequences, intensifies the ongoing concern about the threat. At the same time, lack of understanding of the process of coronavirus appearance and its mutations evokes in people, besides the tension related to being concerned about the threat, uncertainty about the future and doubts as to the expediency of some forms of preventive behaviour. Officially, the WHO provides scientific substantiation of the two main ways of COVID-19 prevention and the actions necessary for overcoming the pandemic - social distancing and vaccination. However, actual behaviour of people is far from corresponding to those requirements in all cases, and, as the result of this, individual effectiveness of anti-pandemic measures goes down. Since all the risks should be considered through the prism of individual ideas about and perception of the threat as the determinant factors in the behavioural intentions (Klimanska, Klymanska, \& Haletska, 2020), popular conspiracy theories behind COVID-19 constitute a permanent obstacle for virus spread prevention and limitation of the pandemic.

Ideas, knowledge and contemplations about the nature of the coronavirus and the mechanisms of development of the pandemic play an extremely important role in the prevention of its spread. Back at the beginning of the pandemic, on February 2, 2020, the WHO (World Health Organisation, 2020) stressed the potential risk of the "infodemic" of unreliable and inaccurate information about the new COVID-19 pandemic that gained an unprecedented speed. In the discourse "being concerned with the threat-compliance with preventive behaviour - restriction/overcoming of the pandemic" a special place goes to 
the COVID-19 conspiracy theories. The outbreaks of diseases often constitute the object of conspiracy theories, in particular, if the nature of the disease is understudied. Conspiracy theories arise in a noticeable opposition to certain mainstream or official information. Such theories normally provide a simple and clear picture of the actual threat, define the uncertain situation, give answers to the question why it happened, who benefits from that and who is to blame (Weigmann, 2018; Wood, 2018), as well as try to explain the reasons with the secret agreement made between powerful actors (Douglas, Sutton, \& Cichocka, 2017).

Analysis of the research proves that the percentage of people supporting the COVID-19 conspiracy theories throughout the globe is high: the percentage of the conspiracy theory supporters in the research selection in Poland varied from $43 \%$ to $56 \%$ (Duplaga, 2020); $24.2 \%$ of the respondents who were 252 health care professionals in Ecuador considered that the virus was purposefully developed in the laboratory (Chen, Zhang, \& Jahanshahi, 2020); $49 \%$ of the respondents who were bachelor students in Nigeria thought that getting infected with COVID-19 is the "exaggeration staged by political leaders and mass media," while 39\% claimed that COVID-19 is "Chinese biological weapon" (Olatunji, Ayandele, Ashirudeen, \& Olaniru, 2020); 35\% of the respondents of the online survey of 2,501 adults in England told that they were prone to believe in the COVID-19 conspiracy theories, while $10 \%$ showed a very high level of belief in the conspiracy theories (Freeman, Waite, \& Rosebrock, 2020); online survey of over 1000 respondents, conducted in April 2020 in Ukraine, proved that $26.57 \%$ of respondents considered that coronavirus had been created artificially as a biological weapon, and $26.27 \%$ thought that the COVID-19 epidemic had been created artificially for the sake of economic and political redistribution of powers in the world (Haletska, Klymanska, \& Klimanska, 2020). The tendency to believe in the artificial creation of an epidemic correlates with the level of distress (Haletska, Klimanska, \& Perun, 2020). All the above data, though, refers to the period of spring of 2020, while the study of the dynamics in the proneness to believe in conspiracy theories has not yet been published. However, analysis of published research points to the identity of both factors, and the consequences of believing in the COVID-19 conspiracy theories globally. It may be stated for sure that conspiracy ideas keep holding top places in people's minds and play an important role in their ideas about COVID-19 and the pandemic, affecting their compliance with prevention measures and their attitude to vaccination process.

Belief in the COVID-19 conspiracy theories has a negative effect on the compliance with official recommendations on social distancing (Freeman, Waite, \& Rosebrock, 2020), increases lack of trust in the state standards (Oleksy, Wnuk, Maison, \& Łyś, 2021; Šrol, Cavojova, \& Mikušková, 2021), causes distrust, negative attitude and vaccination rejection (Romer \& Jamieson, 2020). Conspiracy beliefs are characterised by the ability to be self-supportive, the advocates of conspiracy theories show a great "dedication" to their beliefs, and the popular- 
ity of such ideas is rapidly growing due to influential sources of information speaking in favour of conspiracy theories (Douglas, 2021). Proneness to the COVID-19 conspiracy theories constitutes a barrier for programs and measures aimed at overcoming of the pandemic and prevention of its further possible intensification.

Though supporters of the COVID-19 conspiracy theories seem to keep listening of the recommendations provided by experts in the field of healthcare (Stein et al., 2021), however, the counterarguments voiced by the people they trust and reputable members of the society are potentially capable of reducing the level of conspiracy thoughts expression (Douglas, 2021).

In the COVID-19 pandemic situation a special mission is being realised by medical staff. On the one hand, they are ordinary people living in the conditions of the threat of the global pandemic, but run a much higher risk due to permanent contacts with infected patients, working in the conditions of growing loads. On the other hand, they are enjoying potentially high degree of credibility in relation to all aspects of the pandemic in the eyes of ordinary people. Studies show that manifestation of the belief in conspiracy theories and intentions to undergo vaccination process against COVID-19 greatly depend on the level of education. However, other studies show that it would be erroneous to expect that medical background availability would guarantee definite approval of vaccinations (Verger, Scronias, \& Dauby, 2021). Thus, in France, Belgium and the French-speaking part of Canada, $28.4 \%$ of respondents who are health care professionals claim that they are unwilling to get vaccinated, while $40.9 \%$ of respondents have informed about their own doubts as to the safety of vaccines developed under emergency conditions during the epidemic (Verger, Scronias, \& Dauby, 2021). According to the data of research done in the USA in October $2020,36 \%$ of health care professional were ready to accept the vaccine the moment it would be accessible, while $56 \%$ were not absolutely sure, and $8 \%$ did not intend to get vaccinated. In Germany, the readiness for vaccination among health care professionals is $57 \%$, while $27.6 \%$ cannot decide yet (Nohl, Afflerbach, Lurz, \& Brune, 2021). In fact, similar trends can be traced among health care professionals of different countries as far as quantitative correlation of people trusting vaccines and intending to get vaccinated and those who do not believe in vaccination is concerned. Available researches also point to similar factors for the readiness to get vaccination: higher level of education, male gender, senior age, own load caused by the pandemic (Nohl, Afflerbach, Lurz, \& Brune, 2021).

The aim of this research is to analyse the subjective perception of the effect of the pandemic on life by health care professionals as well as to develop the typology of attitudes displayed by health care professionals in Ukraine to the current COVID-19 situation in general and to the vaccination process in particular. 


\section{RESEARCH METHODOLOGY}

The attitude of health care professionals to the pandemic was studied using the method of a semi-structured interview with open-ended questions. The interviews were conducted with the help of students of the Department of Sociology and Social Work of Lviv Polytechnic National University as well as students of the Department of Psychology of Ivan Franko National University of Lviv. The data was collected during the third wave of the pandemic in Ukraine and the world, from March 11 to April 08, 2021. Transcripts of semi-structured interviews subjected to thematic analysis became the empirical basis for the research. 49 representatives of the health care domain participated in the survey (doctors, middle medical personnel, pharmacists, students of higher medical educational institutions) aged 19-52 (11 men and 37 women).

Thematic analysis as the qualitative data analysis method was used to make analysis of the texts of in-depth interviews, since its methodology enables to outline all possible aspects of the researched problem and situation (Braun \& Clarke, 2006, 2014).

Transcripts were analysed following the standards of comprehensive qualitative analysis method that included a stage-by-stage encoding process. At the structured encoding stage the chief analyst encoded textual elements in each in-depth interview transcript in the way that corresponded to the ways informants used to assess changes in the COVID-19 situation in Ukraine and selected strategies (attempts) for mitigating the threat for themselves.

The second wave of analysis followed the immersion/crystallisation method (Borkan, 1999, pp. 179-194), which is the process that includes deep immersion into the key parts of the encoded data-with regular deviation from them for reflection purposes and in order to reach the other level of theme wording. All the authors have considered the results of such encoding analysis. Regular meetings of the research team, comprehensive discussion of the topics, subtopics and types have contributed to the formulation of conclusions made on the basis of qualitative analysis. Divergences were settled through discussions. 20 typical, in the authors' opinion, interviews are quoted in the text of the article (Annex 1).

\section{DATA ANALYSIS AND INTERPRETATION}

As the result of the interview data processing, the researchers have outlined three topics for analysis:

- Changes occurring in the life of informants under the effect of the circumstances related to the COVID-19 pandemic. These changes were related to both professional and daily life of informants. At the beginning of the study a hypothesis was made that changes in the life of health care professionals will have a different imprint on the professional and daily life. But the hypothesis was not confirmed. The occurring changes were so much 
intertwined that they were difficult to split, that is why decision was passed to unite them within one topic "changes in the conditions of the pandemic";

- Comprehensive situation assessment. This topic was related to the reflection of the whole COVID-19 situation since the beginning of the pandemic and up to the prospects for its further development. Two components were involved in the situation assessment: affective experiences of the informants and cognitions that are ideas about COVID-19. The focus was on assessment of the pandemic situation development prospects by health care professionals as opinion leaders affecting the development of mass moods and behavioural intentions of people having no medical background and knowledge;

- Attitude to vaccination. The attitude to vaccination as the method of overcoming the pandemic was taken into account, as well as assessment of the vaccines available as of the date of the survey was made, together with assessment of the vaccination process in Ukraine and possible ways of promoting it. This behavioural dimension of the attitude of health care professionals to vaccination was considered as a factor affecting the attitude of all other people to vaccination.

After numerous re-readings and encoding of the texts of the conducted interviews, a conclusion was made that critical for the types of health care professionals' response to the COVID-19 risks are two criteria: the informants' idea about the origin of the virus (artificial or natural) and the informants' attitude to the state policy (implementation of policy decisions) selected by the authorities to fight the virus.

The informants' idea about the origin of the virus: artificial or natural. Contemplations about the artificial or natural origin of the virus differ by the degree of black-and-white thinking. The standpoint "I believe in the artificial origin of the virus" covers most of the interviews conducted with the representatives of the health care domain. Sometimes this standpoint is just expressed in a pointblank manner, with no arguments: "that was all done on purpose: the virus was invented" (3) 1, 2, "I think that coronavirus is still of artificial origin" (the word "still" shows that the person has been contemplating over the problem L. K.'s comment) (16), "planned virus, biological weapons aimed to reduce population. Genocide. The virus artificially created in the laboratory" (4). Some informants assumed that this had been a conspiracy aimed to curb population growth (3); to give a chance to some population categories to get some profit (3); to create an artificial virus in the laboratory to pose a threat for the whole mankind, made by China and Russia (17).

The standpoint "everything is not that simple, but I am prone to think like that" was accompanied by the contemplations on the uncertainty, complexity of the virus: "Nothing is finally known about its origin" (5); "It is highly complicated (...) highly different course of the diseases, and its virulence is extremely

1 Informant's number in Annex 1.

2 Hereinafter citations are provided as they were worded by the informants. 
high. Due to this fact I am still prone to think that this was a (...) (a pause and a sigh-proving that the informant feels uncomfortable about expressing this viewpoint-L.K.'s comment) that this was a leak in the laboratory dealing with bacteriological weapons" (2); "I am prone to think that it was artificially made, I don't know whether this opinion has the right to exist, but I think so ..." (11).

Finally, the standpoint "I don't believe in the artificial origin of the virus. The virus is of an absolutely natural origin" was normally accompanied either by the lack of understanding of the question itself, or irritation: "Well, I think we should rather think how to overcome the virus than what it's origin is, since specially trained people should be thinking about its origin and be dealing with it, and our business is to treat and overcome it" (9), "a practicing doctor should think it over how he/she will deal with the issues of organising the treatment process (...) it will be better if everyone does his/her business" (7), which fact can be proven by the words used by the informant - "Similar nonsense is disseminated by the advocates of conspiracy theories, I don't believe in that" (12), or the stress he made in some words - "That is JUST an infectious disease, currently this is an infectious disease and it evokes lethal cases as any infectious disease" (19).

Thus, the informants using the conspiracy substantiation of the COVID19 situation have their own arguments to support the ideas about the artificial origin do not always voice them. Sometimes that happens because of the lack of time, sometimes - due to unwillingness to voice these arguments to the person conducting the interview, however, emotional response to the question about the nature of the virus shows that they are concerned about it. The very explanation of the origin of the virus is rather unclear, vague, sometimes even expressed in the form of hints (to the conspiracy between China and Russia, to powerful people or pharmaceutical companies that may benefit), and sometimes - in the form of rhetorical questions, in order to put the official version to doubt (like "If this virus is of natural origin, then why China does not let the World Health Organisation in to really study this?" (17).

Another criterion for differentiating between the responses of health care professionals to the COVID-19 risks was the attitude of informants to the state policy (implementation of policy decisions) selected by the authorities to fight the virus. In Ukraine the attitude to the authorities and their decisions has traditionally been rather skeptical. That is why, in this background, support of the decisions taken by the authorities in the situation with restrictions for coronavirus spread looks rather strange (opinions split almost into two equal parts). Probably, that is related to the lethal threat posed to the residents and the understanding of the need to rely on one decision-making centre in emergency conditions.

The unambiguous standpoint "I support and assess it positively" was voiced in the following versions: "I think that everything possible is being done in this country to quickly combat the disease" (10), "Our state has introduced certain measures to fight COVID-19 and ensure its prevention" (16). In some cases, the informants mentioned timeliness and efficiency of the first lockdown, in particular (5). It is of interest that in this situation the actions of 
doctors were identified with the actions of the authorities. In fact, they were going hand in hand: "both doctors and the authorities are doing their best, but these measures cannot always be effective" (11). The support of the authorities' actions could be identified in the terms like "the measures are right" (5), "these are good measures" (6), "satisfactory" (8).

The intermediate standpoint as to the actions taken by the authorities was voiced as "a lot is being done, but...". This means that the very availability of some virus-combating action plan is acknowledged, and that it is assessed positively. Critical treatment of the actions taken by the authorities focuses on this "but" factor: "(...) but not the way it should probably be done" (7), "(...) but they should not have allowed the virus to spread (...) they should have closed the borders and not let leave the infected territory, to provide treatment to all those affected locally" (13), "BUT it is necessary for people in real life to follow all those measures" (18), so lack of securing compliance with the norms through certain sanctions is meant by health care professionals.

The unambiguous standpoint "I don't support" goes in parallel with the accusation of the authorities of all traditional sins - "declarative nature" (2), "willingness to get benefits" (2), unwillingness to understand the situation "since, in fact, there are people in power who don't understand what the situation is like, don't realise the whole complexity of the situation since they are reluctant to realise it" (2); " (...) the ruling authorities are managing it all the way they want and need" (3); blunders - "vacation during January holidays at the Bukovel resort" (4); and the same traditional underestimation of one's own role in the change of the situation for the better - "So we, ordinary people, cannot do anything with it to fight the pandemic (...) we are just ordinary people if compared with them, so to say" (3), "It's not our fault that we were born in such a state" (14). The prescription "To replace the Minister of Health - point number one, to replace all ministers - point number two, to elect the new President-point number three, and the Verkhovna Rada - number four. Since it's all about absolute lack of professionalism there!!!" looks absolutely logical against this background of such treatment of the policy implemented by the authorities (17).

Combination of those two criteria leads to the outlining of four standpoints within the above three topics in the types of attitudes of Ukrainian health care professionals to the COVID-19 risks.

Table 1

Types of attitudes displayed by health care professionals to the COVID-19 risks

Origin of the virus / Artificial Natural

Attitude to the policy

implemented by the authorities

\begin{tabular}{ccc}
\hline Approving & Type A. Magical & Type B. Technological \\
& thinking & thinking \\
Critical & Type C. Negativistic & Type D. Critical \\
& thinking & thinking \\
\hline
\end{tabular}

Source: own research. 
The names of the types of thinking ("magical thinking," "technological thinking," "negativistic thinking," and "critical thinking") cannot be regarded to be the ones that correspond to scientific terms, these are rather metaphorical labels reflecting the understanding of these types of thinking. Tables 2-5 present the topics and subtopics within the above-mentioned types.

Type A, which is relatively called "Magical thinking," presupposes trust in the artificial origin of the virus in combination with approving treatment of the policy implemented by the authorities. "Magical thinking" constitutes a part of conspiracy beliefs. Everything happening around and not possible to explain in a rational and well-grounded way is interpreted as the result of a conspiracy. "Magical thinking" as an element of conspiracy beliefs includes the overall stipulation and mutual relation between everything, trust in the objectivity of one's own subjective experience and trust in the capacity of thoughts to directly affect the outer world. "Magical thinking" allows avoiding anxiety, within magical thinking responsibility is fully shifted on to the representatives of the authorities acting within a certain plan and, certainly, correctly and positively.

Changes. The informants with "magical thinking" point to considerable changes in their daily and professional life. Normally this stands for the changes not for the better, but rather the changes for the worse; that is about the balance between negative and positive things, or at least one cannot speak about the shift towards possible positive situation. Drastic negative changes have occurred in lives of many people, so one should not expect any return to "pre-COVID-19" reality. The narration about changes is coloured with negative emotions.

These were the informants of this type that stressed the complications in the performance of their professional duties - "it is difficult to go on call in full outfit, particularly, when it is hot" (11), "it is difficult and uncomfortable during the day (...) to be staying in a mask and rubber gloves" (1). But these are the so called expected complications. The informants speak about the psychological burden-it was psychologically difficult to simultaneously stand both "lack of information" on COVID-10: "what COVID-19 is, how to treat it, how to diagnose it, what complication may arise" (16), and excess of media noises: "the most complicated period for me was the time of mass information, $\mathrm{TV}$, Internet just attacking our minds with this problem. As for me, that was a direct attack on our minds" (13).

Psychological burden of the need for specific communication with patients has also been a problem for doctors: "besides being a doctor, you had to become a psychologist for the patient and his/her relatives to reduce their anxiety and concerns related to the new COVID-19 challenge at least to a certain extent" (16). Doctors are recording the changes in the attitude of patients to them - lack of sincere sparkle in patients' eyes and indirect accusations of the COVID-19 spread.

Comprehensive situation assessment. The second topic identified through indepth interviews is assessment of the coronavirus situation in the dynamics of what the beginning was like and up to its development prospects. This type of 
Table 2

Type A "Magical thinking" (artificial origin of the virus + approving treatment of the policy implemented by the authorities)

Specification

(subtopics)

Examples taken from in-depth interviews

Topic: "Changes occurring under the effect of the circumstances related to the COVID-19 pandemic"

Drastic negative "In fact, my profession has undergone drastic changes, and I doubt that it changes in life will all get back to where it used to be and that we will be able to work in the same mode as before the pandemic" (11)

"Ongoing anxiety" (5)

Changes in the "The attitude of patients to health care professionals has changed. Fear, "doctor - patient" anxiety, certain distrust of the medical staff can be seen in their eyes. Durrelationship ing the traumatic shock which is a pathological condition arising in case of severe bodily injuries people often express their negative opinions about doctors that seem to be the bearers of infection, that is COVID-19" (16) Topic: "Comprehensive situation assessment"

Sources of "I trust only official sources. for me the optimal variant is the official Telinformation - the egram channel where everything is written in a clear and concise manner" basis for situation (11)

assessment "This is the interviewing of scientists, infection disease doctors, virologistsgenetics and medical staff specifically dealing with this problem, who apply treatment in practice, who are in charge of COVID-19 patients" (5)

Emotions and "Emotions are always negative when I see and hear what the number of concerns patients and deceased is" (1),

"Two basic emotions are fear and anger. Fear for the life and health of oneself and one's relatives. And anger, because of the global situation in general" (11)

Assumptions on "Nobody can predict and know when this is going to end (...) we can see it the COVID-19 by the examples of other countries where the situation is just going worse. situation The virus is becoming more active. It spreads very quickly. And this means development that nobody can even predict or know anything beforehand" (1)

"It is not known when the time comes to take away this notorious COVID-19, what we can is just hope for the better and believe that (...) all this terror, fear, and panic will be over one day" (13)

\begin{tabular}{cc}
\hline & Topic: "Setting/disposition concerning vaccination" \\
\hline $\begin{array}{c}\text { Attitude to } \\
\text { vaccination in } \\
\text { general }\end{array}$ & $\begin{array}{c}\text { "Personally I am positive about vaccination since it will help people com- } \\
\text { certain season disease" (16) } \\
\text { "Somebody wants it, somebody does not, but for people in the risk area } \\
\text { that is mandatory" (11) }\end{array}$ \\
$\begin{array}{c}\text { The intention } \\
\text { "Certainly, the opinion of the majority matters, but everybody should } \\
\text { vaccination }\end{array}$ & $\begin{array}{l}\text { make an independent decision whether to undergo vaccination or not" } \\
\text { "I sincerely hope to avoid vaccination" (13) }\end{array}$ \\
$\begin{array}{c}\text { What impedes } \\
\text { "People are afraid that this is something unknown for them, and they } \\
\text { proccination } \\
\text { probably don't believe in vaccines" (11) }\end{array}$ & $\begin{array}{l}\text { "The core fears concerning vaccines are adverse effects that may arise, the } \\
\text { fact that the vaccines were developed within a very short period of time } \\
\text { and may pose a threat in the future with their side effects" (16) }\end{array}$ \\
\hline
\end{tabular}

Source: own research. 
informants has mixed sources from which they take their ideas about COVID19. These are official sources, that is first-hand information coming from health care professionals, but, probably because it is not enough to know just facts, it shows rather strong emotional connection. In general, assessment of the current COVID-19 situation is extremely negative: "the changes are significant and, well, UNPLEASANT" (11), this extraordinary situation has already transformed into the "life style, since over a year we have already learnt to live with this disease" (16), or that it is the "disease that has really got hold of us and won't let us go" (13). Probably, that is why informants of this type do not see any prospects of the development for the better. They generally try not to make any forecasts for the future.

Attitudes to vaccination. A behavioural dimension of an informant's standpoints was identification of his/her attitude to and intentions concerning vaccination. With the representatives of this type the attitude to and the intentions concerning vaccination are rather ambivalent. On the one hand, as health care professionals, they recognise that vaccination is a way of overcoming the epidemic, but this "medical" knowledge does not always work when it comes to their own choice. In this case precaution comes into play-vaccination must be the personal choice of everyone. Thinking on what keeps people from vaccination, the informants, in fact, voiced their own fears and precautions, referring to the uncertainty of both the agent, and the vaccine, lack of immunity study, lack of knowledge about the necessary vaccination frequency. Rather interesting in the background of such treatment of vaccination and its mandatory nature is the conclusion made by one of our informants - "I think mass media affect this process the most, while the doctor's recommendations should be of utmost importance" (5), and this refers not just to ordinary citizens, but to health care professionals as well, since they also fall under the effect of the information appearing in mass media.

Type B got the conventional name "technological thinking." It presupposes belief in the natural origin of the virus in combination with the approving attitude to the policy implemented by the authorities. This sort of thinking aims to solve specific, practical problems and tasks. These are specific tasks that may arise in a health care professional's daily practice, they are not general, and they are limited to the requirements of a specific situation. The summary of the technological thinking operation is specific and leads to practical actions, to the need to act in any situation, even if it is as threatening and unpleasant as the coronavirus one. Specific results of "technological thinking" acquire the form of external manifestations, practical actions (for which the individual is trying to find an algorithm), specific behavioural features. The operation of the "technological thinking" leads to a change in the outer world, the situation in accordance with the objectives of its subject. This is the standpoint of a professional who does not have time to think over philosophical problems of the virus origin and correctness or incorrectness of the steps taken by the authorities. One perceives the situation with coronavirus as the situation that requires maximum professional knowledge, and, most importantly, skills that 
will enable him/her to better overcome the unpleasant outcomes related to the negative consequences of COVID-19.

Table 3

Type B "Technological thinking" (natural origin of the virus + approving attitude to the policy implemented by the authorities)

\begin{tabular}{|c|c|}
\hline $\begin{array}{l}\text { Specification } \\
\text { (subtopics) }\end{array}$ & Examples taken from in-depth interviews \\
\hline \multicolumn{2}{|c|}{$\begin{array}{c}\text { Topic: "Changes occurring under the effect of the circumstances related to the COVID-19 } \\
\text { pandemic" }\end{array}$} \\
\hline No drastic changes & $\begin{array}{l}\text { "No drastic changes have occurred, we live with the quarantine and } \\
\text { that's it, probably, there is a bit more work at the workplace now" (6) } \\
\text { "No special changes have occurred. It was necessary to learn to live } \\
\text { with it" (10) }\end{array}$ \\
\hline $\begin{array}{l}\text { Changes in the } \\
\text { "doctor - patient" } \\
\text { relationship - tech- } \\
\text { nology details }\end{array}$ & $\begin{array}{l}\text { "How do we explain a patient that she/he should follow the quar- } \\
\text { antine (...) vitamin therapy, water-intake regime, home-stay regime } \\
\text { (...) how do we calm down a patient for him/her not to be that much } \\
\text { worried about the fact that she/he has already got this disease" (8) }\end{array}$ \\
\hline \multicolumn{2}{|r|}{ Topic: “Comprehensive situation assessment” } \\
\hline $\begin{array}{l}\text { Sources of informa- } \\
\text { tion - the basis for } \\
\text { situation assessment }\end{array}$ & $\begin{array}{l}\text { "Medical literature, it is approved, it undergoes validation and is } \\
\text { edited, scientific articles (...) are written by qualified people }(. . .) \\
\text { professors" (6) } \\
\text { "I trust orders" (8) }\end{array}$ \\
\hline $\begin{array}{l}\text { Emotions and con- } \\
\text { cerns }\end{array}$ & $\begin{array}{l}\text { "I am ok about it, I take it for granted, I perceive this situation in a } \\
\text { realistic way"(6) }\end{array}$ \\
\hline $\begin{array}{l}\text { Assumptions on the } \\
\text { COVID-19 situation } \\
\text { development }\end{array}$ & $\begin{array}{l}\text { "I think everything is going to be alright anyway. Vaccine is al- } \\
\text { ready there, the main thing is not to be afraid and not to give up!" } \\
\text { (9) } \\
\text { The situation with coronavirus "(...) will continue until most resi- } \\
\text { dents fall ill, (...) probably, vaccination will help; the pandemic will } \\
\text { be gradually subsiding, therefore, sooner or later it will be over" (6) }\end{array}$ \\
\hline \multicolumn{2}{|r|}{ Topic: “Setting/disposition concerning vaccination" } \\
\hline $\begin{array}{l}\text { Attitude to vaccina- } \\
\text { tion in general }\end{array}$ & "We are going to be saved through vaccination" (10) \\
\hline $\begin{array}{l}\text { Vaccination -techno- } \\
\text { logical details }\end{array}$ & $\begin{array}{l}\text { Term - "It is necessary to undergo vaccination within a short period } \\
\text { of time" (10) } \\
\text { Vaccine - "CoviShield, since it has been approved by the World } \\
\text { Health Organisation and many health care professionals have al- } \\
\text { ready been vaccinated with it, and this deserves attention" (9) } \\
\text { Consistency - "It is necessary to undergo vaccination. At first - for } \\
\text { health care professionals, risk groups, and then, respectively, for all } \\
\text { the residents" (8) }\end{array}$ \\
\hline
\end{tabular}

Source: own research.

Changes. The informants with "technological thinking" are rather calm in their treatment of the whole situation with the virus and pandemic. Some of them just point it out that nothing has changed considerably, just the number of patients has increased, more time and attention is paid to COVID-19 patients, so they have more work, but with time "we got accustomed, adapted" (10). 
They point out to some technological details, work points, they do not try to think globally, to make conclusions about the whole mankind, they are interested in a specific patient, specific recommendations. This type of informants has got a clearly articulated realisation of the fact that doctor affects patients with his/her behaviour: "doctors - they are always 'on alert' (...) one should always think with no emotions and be self-confident in order to at least not make people panic" (9). That does not mean that they have no emotions about the situation at all - "fear - it is always there in the depth, covered under the mask of the quiet" (9). It is of interest that such informants almost do not tell what has been the most complicated thing. The impression is that they simply do not notice this question in the interview, or rather speak about the difficulty of getting accustomed to the new conditions, but immediately indicate that they have already gone through that period.

Comprehensive situation assessment. Assessing the COVID-19 and the pandemic situation, the informants with "technology type of thinking" mainly use specialised medical literature. They consider that medical information is more reliable than the information on the Internet. In addition to medical literature, such informants also look through official information on the website of the Ministry of Health (9). Informants acknowledge that there is a lot of information on coronavirus, but they trust only the information suggesting clear orderlike algorithms of technological nature.

Answers to the questions with this type of health care professionals cannot be called emotionally coloured. No catastrophe is felt in their words, they show rather positive and realistic work mood and the hope that "everything will be fine" (8). These people feel more optimistic (they call it their resources in the COVID-19 situation) in cases "when a patient recovers after this disease" (8); "the number of people who overcome the disease and the people wearing mask, following social distancing, complying with the quarantine conditions and (...) the fact that the work of health care professionals is appreciated" (9). The word which is rather often repeated when informants are describing the whole COVID-19 situation is responsibility. They realise that they are in the frontline, among those who are faced with this dangerous virus: "(..) with coronavirus, health care professionals got more work that requires higher responsibility, I am the first to examine my patients and I have to identify the symptoms, I am responsible for their health and life" (9).

Assessing the coronavirus situation development prospects, the representatives of the "technological thinking" are more prone to predict positive developments. Though, everybody mentions one obligatory condition - "ending of the pandemic depends on people, and on how they follow quarantine conditions, though they are now neglected by many, probably, that is why everything is so long" (9), "I have a great hope that our residents will be conscious about the disease (...) and we will overcome this pandemic, with no significant losses (...). In my opinion, everything should end soon, since we are conscious citizens and we will take all the safety steps to overcome the disease" (10). 
Table 4

Type C "Negativistic thinking" (artificial origin of the virus + critical treatment of the policy implemented by the authorities)

\begin{tabular}{cc}
\hline $\begin{array}{c}\text { Specification } \\
\text { (subtopics) }\end{array}$ & Examples taken from in-depth interviews \\
\hline
\end{tabular}

Topic: "Changes occurring under the effect of the circumstances related to the COVID-19 pandemic"

Drastic changes "Significant, extreme, drastic" (2)

"We have, in fact, lived through such lack of knowledge and (...) we WERE not ready, and generally nobody was ready for the events that were developing so quickly" (17)

"Dead-end" (17)

Changes in "That is something I cannot fully grasp: as a doctor, why some patients the "doctor with complicated chronic diseases, if infection comes to their organism, -patient" recover, at least stay alive; while a certain category of people who have relationship - never had any diseases, used to be healthy people, went in for sports, have, what was most unfortunately, passed away" (14)

complicated "LACK OF KNOWLEDGE, LACK OF ORGANISATION continues! That is why our current AUTHORITIES, as I see, have failed in everything that they could, and it's really awful to watch all this" (20)

\section{Topic: "Comprehensive situation assessment"}

Sources of "The main source of information are publications on the Internet information

- the basis

for situation assessment

Information (...) I follow some statistics provided by the Ministry of Health, read recommendations from foreign scholars, compare with what infection disease doctors recommend" (2)

"groups in social media, the website of the Ministry of Health; interviews with doctors, our doctors (...), and those from regions. Well, and from my acquaintances who also work in hospitals" (3)

avalanche

"So much information arrives, and that is the sort of information people don't know whether to trust or not (...) we are overloaded with information, and you already don't know whether it is true or you are deceived" (3)

"I already don't want to hear about it, it is everywhere - on the phone, on TV, at work, that is too much about coronavirus" (14)

Lack of "I don't have a clear single source which I trust, I read something trust in any everywhere, analyse it and take something for me, at the same time information denying and rejecting other things" (2).

"There are a great many secondary articles, some high-profile headlines carrying no information or even deceiving people, confusing them" (2)

Emotions and "Mainly, pain, fear (...) And anger with the people who are not conscious concerns of what danger they are putting themselves at (...)" (2)

Assumptions "We will have to live with this not for one, not for three, and not for four on the years. Since the virus is constantly mutating and, respectively, we cannot say COVID-19 that it has disappeared, IT WILL NOT. The way different flu types do not situation disappear. Therefore, we will have to get accustomed to living with this" (17) development "It will all end up in a natural selection, some people will die, others will get immunity to it" (14)

\section{Topic: "Setting/disposition concerning vaccination"}

Attitude to "That is the only way to quickly end up with this coronavirus epidemic" (20)

vaccination in general "I believe that the vaccine will win. The way vaccine for smallpox won, as vaccine won over cholera, I think the same goes for COVID-19. Common sense and vaccine!" (14) 
Intention "Vaccination should probably take place, but now I am cautious about it. I to undergo personally will not undergo vaccination yet" (2)

vaccination "I will definitely not undergo vaccination this spring" (17)

Problems in the "Vaccines have not got through all the stages of testing" (14)

situation with "So far there is not enough vaccine, and even those willing to undergo vaccination vaccination are in the end of the queue, and it is not clear whether it will be their turn one day, whether there will be enough vaccine for them" (14) "When health care professionals are forced to undergo vaccination, and they are reluctant to, they are made to do this in different ways. Our officials dare to say that they should be dismissed from work (...) Well, that absolutely does not contribute to the growing trust of residents in the procedure" (2)

Source: own research.

Attitude to vaccination. Attitude of this group of informants to the vaccination process is definitely positive. Some of them have already undergone the vaccination, some were waiting for their turn. And they realise that "people are divided into two types: some support vaccination, others resist it. Vaccines have always been there, and people have always been afraid of them and cautious about them, so, no wonder, that the same is happening in the COVID-19 situation" (9). To have fewer people resisting, "correct propaganda by doctors, the Ministry of Health should be organised" (10). And again, this group of informants is interested in technological details - when the vaccination should be done, with what vaccine and in what sequence.

Type $C$ in our typology was called "negativistic thinking." It combines ideas about artificial origin of the virus and critical treatment of the policy implemented by the authorities. People with that type of thinking, while assessing any situation, first outline the characteristics it lacks. A negativist would say "The weather is not bad, it is not cold outdoors." And these characteristics are not always negative. In their language, negativists most frequently use expressions with "not" and focus on non-correspondences.

Changes. The changes in the lives of those informants are not just significant, but even drastic. Sometimes the balance of such people is disturbed with trivial things one could probably not pay attention to. They have an acute sense of injustice: "And what I get most irritated with in my daily life is the fact that I cannot reach my workplace. I need to stand in a queue even in spite of the fact that I have a certain document certifying the fact that I have some preferences for being the first in the queue. They should let me in since I am a doctor - I am going to my workplace, but people are highly irritated with this, and showing this document every time means that you will hear not very pleasant things said to your back, though it seems to me it should be just the opposite" (14). Speaking about changes in the professional domain, the informants point out that in spite of inconveniences they feel due to wearing a mask, gloves, shields, glasses, and medical gown, the most difficult part of the situation is the lack of understanding as to what is happening $(14,20)$. 
Comprehensive situation assessment. Negativists are distinguished from other types by the use of many sources of information: Internet publications, statistics of the Ministry of Health, interviews with health care professionals, groups in social media, medical literature published abroad, TV. Informants stress that they do not fully trust any of the information sources. The reasons for lack of trust are different. Distrust is caused by the amount of information that has literally flooded the whole information space. If we speak about the Internet and social media, the informants mention that some information are often fake, while traditional mass media are trying to draw attention to the news via creation of "awful pictures": "when our TV, radio, press showed those awful shots from Italy, Lombardy, Spain, that left people's heads spinning, and they did not understand how it is, what it is, what it all should be like" (11). In the opinion of one of the informants, this activity of the media has given birth to a rather interesting effect in the treatment of health care professionals. Among non-medical staff, a myth about a medical conspiracy appeared: "(...) that is all the conspiracy among corporations, and that is all not true (...) they say that if doctors did not get salary bonuses, the virus would have been won over long ago" (14). The only accurate information, as one informant mentioned, "we are now already convinced that the pandemic EXISTS" (4).

In the background of total distrust in the information coming from different sources, the perception of the risk of COVID-19 is highly emotional. Fear, lack of peace, uncertainty about today and the future. The opinion of one of the informants has turned out to be rather interesting: he mentioned how he had come to understanding that the coronavirus situation was getting worse: "more finance started being allocated, additional payments were coming, and we came to understand that, in general, the situation had changed for the worse" (20).

Probably, lack of validated information and the emotional character of treating the COVID-19 threat affected the vision of the pandemic situation development prospects. The critical nature of the COVID-19 situation is seen by health care professionals not in the lack of beds for patient hospitalisation, but rather in the lack of medical staff: "And who is going to service those beds? There are not enough people" (2).

One of the statements is also that the pandemic is going to end "(...) as every virus is of some cyclic character by nature. It should all end up one day" (2). However, the informants with "negativistic thinking" do not dare to predict when this will happen, referring to the complexity of the situation. Instead of mentioning dates of the pandemic completion, informants rather point to the conditions of its completion: after most residents fall ill and their immunity is back or after the "natural selection."

Attitudes to vaccination. Most of the informants with "negativistic type of thinking" do not intend to undergo vaccination, though they recognise that, to put it in abstract terms, vaccination is the only way to finish the pandemic. It is worth noticing that health care professionals are talking about vaccination for residents, and not for health care professionals. According to them, health 
care professionals do not need vaccination since "almost $70-80 \%$ of health care professionals have already got the disease" (17).

Almost all the negativists are very critical about the vaccines used in Ukraine, claiming that too little time has passed to produce a high-quality vaccine, test it and examine its possible adverse effects. If they had a chance to select the vaccine, they would prefer "Pfizer (...) that is one of the vaccines that has been tested more" (3), or some other European or American vaccine (14). The conclusion is - "it would be good to undergo vaccination abroad" (4).

The whole situation with the vaccination process is characterised by health care professionals as a problematic one. They see the problem in the lack of high-quality vaccine that has undergone a full testing cycle, as well as in the insufficient number of vaccines in general. The attitude to the organisation of the whole process is also highly critical. Negativists think that, in fact, the vaccination process may be considered compulsory.

Health care professionals also point to an absolute uncertainty in the determination of the terms for second vaccine administration: "nobody knows for sure whether it is 3 weeks or 3 months, normally it is 3 weeks, while revaccination should be at least after a month. Why have they started speaking about 3 months now - nobody knows (...) here, in this aspect, our state is somehow... Either it does not know itself, or the manufacturer does not tell it, or the manufacturer itself does not know since there has been no testing on people. It may be said that we are a sort of guinea pigs, experiments are staged on us as to after what period one should undergo vaccination" (14).

In fact, any actions of the authorities aimed to regulate the whole COVID19 situation are subjected to destructive criticism. The main accusation was voiced in a rather radical way - "If Ukraine manufactured vaccines, I guess, the majority of residents would have already undergone vaccination, but nobody does it here (...) all research and technical institutions are closed (...) nobody is interested in it. That is not oil, not gas, coal, not grain to be sold. Here it is necessary to invest into it, this is about health. Our state just won't invest money into it" (14).

In the opinion of those informants, it is necessary to develop trust in the vaccine and the policy around vaccination: "a smart campaign should be conducted. A smart campaign presupposes comprehensive awareness of residents, showing them positive sides in the same way as available complications were openly described" (2). A communicative campaign does not involve compulsory nature - for people also to have the right to choose. State officials should show their personal examples of vaccination only, and that personal example should be shown in a smart way, and not just on TV: “judging by TV, I myself have seen that our officials undergo vaccination, and vaccine seems to be administered, but when the video with a larger resolution, you can see that the needles in syringes are bent to the other side, and it's like being vaccinated to show it to people, while this vaccine does not get into the body, even they do not have it administered" (3). 
Table 5

Type D "Critical thinking" (natural origin of the virus + critical attitude to the policy implemented by the authorities)

\begin{tabular}{cc}
\hline $\begin{array}{c}\text { Specification } \\
\text { (subtopics) }\end{array}$ & Examples taken from in-depth interviews \\
\hline
\end{tabular}

Topic: "Changes occurring under the effect of the circumstances related to the COVID-19 pandemic"

Fixed changes "Limitations in movement, the need to remove unnecessary contacts with people, limitations in daily life, as to sports, visiting friends" (7) "Changes are primarily related to work, I have got much more work since I work in hospital, the income has remained the same, unfortunately, they have not taken great care of us, BUT THIS IS OUR REALITY, and also even the way of living has changed, reaching the workplace, and well, that is rather complicated" (18)

Changes in the "I am disoriented and feel tense due to the fact that I don't have a clear "doctor - patient" understanding of what the danger is and how the risk could be rerelationship - what duced" (12)

has been the most "It is sometimes difficult to communicate with a person (...) you can complicated thing see all the symptoms (...), that this is coronavirus, but the person says 'well, no, I have been throwing snow away, and now I cough,' that is very sad that she/he can be the carrier, and it is difficult to convince that one should be staying at home and not go anywhere... It is very difficult SOMETIMES to persuade, difficult" (15)

\begin{tabular}{|c|c|}
\hline \multicolumn{2}{|r|}{ Topic: "Comprehensive situation assessment" } \\
\hline $\begin{array}{l}\text { Sources of } \\
\text { information -the } \\
\text { basis for situation } \\
\text { assessment }\end{array}$ & $\begin{array}{l}\text { "These are documents... of the Ministry of Health, as well as some in- } \\
\text { ternational information bulletins we are given, tools for better under- } \\
\text { standing and treatment of this disease" (7). } \\
\text { "Conferences, our professional ones, special meetings taking place on- } \\
\text { line (...), I take there everything I need" (15) }\end{array}$ \\
\hline $\begin{array}{l}\text { Information } \\
\text { assessment }\end{array}$ & $\begin{array}{l}\text { "Concerning information, I (...) TRUST ONLINE CONFERENCES } \\
\text { THE MOST, the conferences held by experienced infection disease } \\
\text { doctors, and... I can TELL that everything I have heard at conferences } \\
\text { is really true, IT IS HAPPENING THAT WAY, everything related to } \\
\text { COVID-19 (18) } \\
\text { "I read rather a lot in Telegram - information of different quality, even } \\
\text { trash. Since today, to understand the COVID-19 situation, one should } \\
\text { also read trash in Telegram, since it's Telegram that is often a guidance } \\
\text { for passing top-level decisions" (12) }\end{array}$ \\
\hline $\begin{array}{l}\text { Emotions and } \\
\text { concerns }\end{array}$ & $\begin{array}{l}\text { "The sense of powerlessness, dead-end and tragedy of all that is hap- } \\
\text { pening has also affected me" (7) }\end{array}$ \\
\hline $\begin{array}{l}\text { Current situation } \\
\text { with COVID-19 }\end{array}$ & $\begin{array}{l}\text { "For me, coronavirus has now become a disease that will keep existing } \\
\text { forever, yes, sure, vaccination will help to curb the dissemination, but } \\
\text { gradually we will start treating is as other viral infections" (12) } \\
\text { "We don't have a way out, we don't have where to hide from this..." (15) }\end{array}$ \\
\hline $\begin{array}{l}\text { Assumptions } \\
\text { concerning the } \\
\text { COVID-19 situation } \\
\text { development }\end{array}$ & $\begin{array}{l}\text { "I can tell that the research is not over, the risk of patient's death is } \\
\text { affected by different factors, including the place where she/he under- } \\
\text { goes treatment, age, and health status" (12) } \\
\text { "COVID-19 will not disappear, but there will not be hundreds of deaths } \\
\text { on a daily basis, as it is the case now, since rooted diseases behave different } \\
\text { than new ones. But finally, the time will come after the pandemic when life } \\
\text { gets stabilised thanks to the vaccine or immunity to this virus" (12) }\end{array}$ \\
\hline
\end{tabular}




\begin{tabular}{cc}
\hline & Topic: "Setting/disposition concerning vaccination" \\
\hline $\begin{array}{c}\text { Attitude to } \\
\text { vaccination }\end{array}$ & "Not to wait until the whole mankind falls ill. We should try to bring in \\
and intention & "Vaccination is the only chance to stop the coronavirus epidemic, \\
to undergo & though most people are afraid of undergoing vaccination, the most \\
vaccination & $\begin{array}{c}\text { important thing must be that all vaccines approved by the WHO are } \\
\text { efficient and safe" (12) }\end{array}$ \\
Problems in the "Mass media may have both a positive, and a negative impact, they \\
situation with \\
vaccination \\
$\begin{array}{l}\text { "Mosth both advertise, and tell that the vaccine is of poor quality..." (19) } \\
\text { understandings about the vaccine. It has not been well-studied, it is } \\
\text { not normal when people are vaccinated while at the same time there } \\
\text { appear a lot of new facts about the medicine" (12) }\end{array}$
\end{tabular}

Source: own research.

One more type (Type D) of attitude to the COVID-19 situation, "critical thinking," presupposes believing in the natural origin of the virus in combination with the critical attitude to the policy implemented by the authorities. "Critical thinking" presupposes the process of analysis, synthesis and substantiation of the assessment of the reliability and value of information, ability to see the situation globally and with due account of the context, to find the reasons and alternatives. Such kind of thinking helps to generate or change one's standpoint on the basis of facts and arguments, to adequately apply the results received in relation to different problems and to pass well-balanced decisions - what to trust and what to do next.

Changes. The informants belonging to the "critical thinking" type normally trace changes both in their daily and their professional life. But that, actually, stands for tracing of changes in specific domains. They trace changes as if they needed to enumerate all of them in a certain order: changes in the organisation, changes in regulation, changes in the forms of patient observation, changes in communication with colleagues.

What makes the life of people with "critical thinking" most complicated is non-understanding of the situation and a respective inability to explain the whole risk of the situation with COVID-19 to patients. With many informants of this type of thinking, all interests shift towards their professional activity. Most of them, when asked about changes, give answers related only to their job.

Thus, the attitude of this type of health care professionals to the changes that have occurred due to the coronavirus is rather calm. They trace them in order to decide what they should do with them next.

Comprehensive situation assessment. People with this type of "critical thinking" normally assess information coming from different sources. It is conspicuous that the question is not at all about trust in information. There is official information, and it should be the guidance in the managerial decision-making. It is acknowledged that information of professional nature should be most trusted, but it is worth getting acquainted with information coming from many 
sources, to know both true and false information - that enables to solve the problem with trust independently, with no prompts.

Emotions are added to both information and situation assessment, but the impression is that these emotions are controlled. The informants mention their emotions and concerns at the beginning of the pandemic and indicate that this is already in the past.

Sufficiency of information and emotional control enable such people to assess the current COVID-19 situation as a working and unavoidable one. Some of them are even trying to find some positive aspects about the whole situation - "in fact, I am really grateful to my destiny for bringing in such circumstances that were considered as almost the end of the world, since my life has changed greatly" (12).

Assessment of the pandemic and COVID-19 situation is made as if from aside, they analyse it in an abstract way, almost with no personal involvement (but for cases when the situation affected the life of their relatives): "On the one hand, the unavoidability of events, but, on the other hand, the opportunity to influence them, it IS still there. That is optimism" (7). The informants of this type, in fact, do not predict how the situation will develop, and this is rather not because they are afraid of doing this, but because they do not have enough input information to make any forecast. Referring to the opinions of reputable people, they rather think in scenarios, recall similar situations from the past with different types of viruses and also project them onto the current coronavirus situation.

In general, this group of informants, though predicting possible situation deterioration (virus mutation, continuation of quarantine measures, but with no time parameters), voice statements of the type "everything will be fine" "Well, I think the problem will anyway be handled, and I think that vaccination will be there and people will realise the need for vaccination" (7), "everything is going to be alright! No worry. I think everything is going to be alright!" (19).

The rationality of this type of health care professionals also prevails in their attitude to vaccination. They are positive in their assessment of vaccination and claim "in chorus" that they want to undergo vaccination against coronavirus (and some have already done this).

As to what may be impeding the vaccination process is Ukraine, health care professionals have outlined several circumstances. The first one is existence of a powerful anti-vaccination campaign in this country, anti-vaccination trends which "by inertia have come to this campaign with vaccination against coronavirus" (7), also supported by the anti-vaccination policy "conducted for years, years, and years, and the very state discredited this method in general at some point of time when poor-quality vaccines were imported, when were there different adverse effects, when these vaccines were inefficient" (15).

Secondly, actions of mass media are mentioned as one more impeding factor, since "they spread some, probably, unstudied materials" (18), while they could be promoting the vaccination process. Finally, a considerable factor that is probably impeding the willingness of residents to undergo vaccination 
is controversial nature of information about vaccines, as health care professionals think. Misunderstanding about vaccines having some political colouring is " $(. .$.$) an additional factor of political nature... this whole story with vaccine$ Sputnik which our northern neighbour is offering the European countries, us including, under different pretexts" (7).

\section{CONCLUSION}

Therefore, the study aimed to analyse the standpoint of health care professionals as the key players on the battlefield with the pandemic and in the vaccination process, as far as the origin of the virus and settings concerning vaccination through the prism of changes that have occurred in their life in the conditions of the COVID-19 pandemic are concerned. The study conducted aimed to primarily analyse two aspects. First, the one related to the quality of life and psychological well-being of people: how health care professionals who have been staying in the conditions of daily face-to-face opposition to the coronavirus in the conditions of higher danger of catching the infection, growing work load, besides all the restrictions ordinary people are faced with, live and regulate their professional and personal life. Thanks to a qualitative research it became possible to identify general trends, attitudes and patterns of living in the conditions of the pandemic. And though the life of health care professionals has obviously changed, imposing rigid restrictions, no explicit concerns about the catastrophic nature, serious affective reactions or complaints about frustrating life have been traced. Most studies, nevertheless, testify to the negative consequences of the pandemic for the mental health of health care professionals as the result of objective increase in both danger and professional load. Therefore, absence of clear complaints may be caused by the general fatigue (its availability is indisputable, though it has not been in the focus of our researches) and burnout.

The second aspect that is directly related to the life of mankind in general in the nearest future and further development of the pandemic situation is the attitude to vaccination and the readiness to undergo vaccination. The importance of this readiness is perceived as a potential personal contribution to the development of the shield against the virus spread. Two vectors of the contemplation discourse among health care professionals concerning the current situation and the pandemic development prospects for the future have been identified: idea about the origin of the virus (artificial or natural) and attitude to the policy of the state and actions of the authorities. Four typical standpoints in the attitude of health care professionals were outlined - "magical thinking," "technological thinking," "negativistic thinking," "critical thinking" - which enable to reflect the most typical cognitive mechanisms. In fact, almost $25 \%$ of health care professionals are prone to interpret the origin of the virus as artificial, and this result does not differ from the research data from other countries. Analysis of the interviews conducted, however, does not identify high level of pre-disposition of health care professionals to conspiracy theories, but requires 
a detailed study using quantitative methods. In the considerations about the origin of the virus and the treatment of vaccination, the motive of distrust in the actions of the state, expectations of some catch-22, dirty trick and pitfall can be traced, and, in combination with objective lack of verified information about the vaccination efficiency, this affects the intention to undergo vaccination in a negative way. The results of the research show that proneness to medical conspiracy theories is greatly related to personal characteristics, trust in the world and faith in justice, the very situation with understanding and verification, as well as transparency and efficiency of the state programs and actions. Medical education considerably reduces the striving for conspiracy theories, but in the context of lack of information, chaos and lack of consistency of official state programs and actions, through the prism of distrust, this has a considerable negative effect on the efficiency of vaccination campaigns. The approach embracing collection and analysis of high-quality data has enabled to enrich the data about the changes occurring in the coronavirus pandemic situation, while the limited sample scope makes it impossible to make a wider quantitative comparative analysis. Therefore, the outlined typology determines available trends that require further research using quantitative methods.

\section{ANNEX 1}

\section{Informant description}

\begin{tabular}{cc}
\hline $\begin{array}{c}\text { Informant } \\
\text { number }\end{array}$ & Informant description \\
\hline 1 & Woman, 47 years of age, pharmacist \\
2 & Woman, 48 of age, microbiologist \\
3 & Woman, 43 years of age, pharmacist \\
4 & Woman, 48 years of age, medical nurse in a family outpatient facility \\
5 & Woman, 50 years of age, doctor \\
6 & Man, 25 years of age, doctor \\
7 & Man, 52 years of age, chief physician of a hospital for children \\
8 & Woman, 51 years of age, medical nurse in a child polyclinic \\
9 & Woman, 23 years of age, village medical assistant \\
10 & Woman, 45 years of age, medical nurse of a polyclinic \\
11 & Woman, 25 years of age, medical nurse \\
12 & Woman, 26 years of age, pharmacist \\
13 & Woman, 41 years of age, doctor \\
14 & Woman, 50 years of age, admission unit doctor \\
15 & Woman, 48 years of age, doctor-gynecologist \\
16 & Woman, 26 years of age, family doctor \\
17 & Man, 45 years of age, gynecologist \\
18 & Woman, 36 years of age, doctor-laboratory assistant \\
19 & Woman, 50 years of age, doctor \\
20 & Man, 44 years of age, doctor \\
\hline
\end{tabular}

Source: own research. 


\section{REFERENCES}

[1] Borkan, J. (1999). Immersion/Crystallisation. In: B.F. Crabtree \& W.L. Miller (Eds.) Doing qualitative research (pp. 179-194). Thousand Oaks, CA: Sage Publications.

[2] Braun, V., \& Clarke, V. (2006). Using thematic analysis in psychology. Qualitative Research in Psychology, 3(2), 77-101. doi: 10.1191/1478088706qp063oa.

[3] Braun, V., \& Clarke, V. (2014). What can "thematic analysis" offer health and wellbeing researchers? International Journal of Qualitative Studies on Health and Well-being, 9, Article 26152. doi: 10.3402/qhw.v9.26152.

[4] Chen, X., Zhang, S. X., Jahanshahi, A. A., Alvarez-Risco, A., Dai, H., Li, J., \& Ibarra, V. G. (2020). Belief in a COVID-19 conspiracy theory as a predictor of mental health and well-being of health care workers in Ecuador: Cross-sectional survey study. JMIR Public Health and Surveillance, 6(3), Article e20737. doi: 10.2196/20737.

[5] Douglas, K. M., Sutton, R. M., \& Cichocka, A. (2017). The psychology of conspiracy theories. Current Directions in Psychological Science, 26(6), 538-542. doi: 10.1177 /0963721417718261.

[6] Douglas, K. (2021). Are conspiracy theories harmless? The Spanish Journal of Psychology, 24, Article E13. doi:10.1017/SJP.2021.10

[7] Duplaga, M. (2020). The determinants of conspiracy beliefs related to the COVID-19 pandemic in a nationally representative sample of internet users. International Journal of Environmental Research and Public Health, 17(21), Article 7818. doi:10.3390/ijerph17217818.

[8] Freeman, D., Waite, F., Rosebrock, L., Petit, A., Causier, C., East, A., Jenner, L., Teale, A. L., Carr, L., Mulhall, S., Bold, E., \& Lambe, S. (2020). Coronavirus conspiracy beliefs, mistrust, and compliance with government guidelines in England. Psychological Medicine, 1-13. doi: 10.1017/S0033291720001890.

[9] Haletska, I., Klymanska, L., \& Klimanska, M. (2020). Quarantine April in Ukraine: Thoughts, experiences, behaviour faced with the threat of COVID-19. Psychological Journal, 6(5), 18-36. doi: 10.31108/1.2020.6.5.2.

[10] Haletska, I., Klimanska, M., \& Perun, M. (2020). COVID-19, lockdown and family life in a new reality. Psychological Journal, 6(9), 40-57. doi: 10.31108/1.2020.6.9.4.

[11] Klimanska, M., Klymanska, L., \& Haletska, I. (2020). The lens, frames and patterns of Ukrainians: How perception of threat and risk determines behaviour in the COVID19 situation. Journal of Education Culture and Society, 11(2), 444-460. doi: 10.15503/ jecs2020.2.444.460.

[12] Nohl, A., Afflerbach, C., Lurz, C., Brune, B., Ohmann, T., Weichert, V., Zeiger, S., \& Dudda, M. (2021). Acceptance of COVID-19 vaccination among front-line health care workers: a nationwide survey of emergency medical services personnel from Germany. Vaccines, 9(5), Article 424. doi: 10.3390/vaccines9050424.

[13] Olatunji, O. S., Ayandele, O., Ashirudeen, D., \& Olaniru, O. S. (2020). "Infodemic" in a pandemic: COVID-19 conspiracy theories in an African country. Social Health and Behaviour, 3(4), 152-157. doi: 10.4103/SHB.SHB_43_20.

[14] Oleksy, T., Wnuk, A., Maison, D., \& Łyś, A. (2021). Content matters. Different predictors and social consequences of general and government-related conspiracy theories on COVID19. Personality and Individual Differences, 168, Article 110289. doi: 10.1016/j.paid.2020.110289.

[15] Romer, D., \& Jamieson, K. H. (2020). Conspiracy theories as barriers to controlling the spread of COVID-19 in the U.S. Social Science \& Medicine, 263, Article 113356. doi: 10.1016/j. socscimed.2020.113356.

[16] Šrol, J., Cavojova, V., \& Mikušková, E. B. (2021). Social consequences of COVID-19 conspiracy beliefs: Evidence from two studies in Slovakia. PsyArXiv. doi: 10.31234/osf.io/y4svc.

[17] Stein, R. A., Ometa, O., Pachtman Shetty, S., Katz, A., Popitiu, M. I., \& Brotherton, R. (2021). Conspiracy theories in the era of COVID-19: A tale of two pandemics. International Journal of Clinical Practice, 75(2), Article e13778. doi: 10.1111/ijcp.13778.

[18] Verger, P., Scronias, D., Dauby, N., Adedzi, K. A., Gobert, C., Bergeat, M., Gagneur, A., \& Dubé, E. (2021). Attitudes of healthcare workers towards COVID-19 vaccination: A survey in France and French-speaking parts of Belgium and Canada, 2020. Euro Surveillance: Bulletin Europeen sur les Maladies Transmissibles = European Communicable Disease Bulletin, 26(3), 2002047. doi:10.2807/1560-7917.ES.2021.26.3.2002047. 
[19] Weigmann, K. (2018). The genesis of a conspiracy theory: Why do people believe in scientific conspiracy theories and how do they spread? EMBO Reports, 19(4), Article e45935. doi: 10.15252/embr.201845935.

[20] Wood, M. J. (2018). Propagating and debunking conspiracy theories on Twitter during the 2015-2016 Zika virus outbreak. Cyberpsychology, Behaviour and Social Networking, 21(8), 485-490. doi: 10.1089/cyber.2017.0669.

[21] World Health Organisation. (2020). Novel Coronavirus (2019-nCoV) situation report-13. Retrieved from https://www.who.int/docs/default-source/coronaviruse/situation-reports/20200202-sitrep-13-ncov-v3.pdf. 